\title{
Empty Soul Syndrome
}

\author{
José Humberto Cardoso Resende \\ Alfredo Nasser College (UNIFAN), Goiânia, Brazil \\ Email: jresen99@hotmail.com
}

How to cite this paper: Resende, J.H.C. (2018) Empty Soul Syndrome. Journal of Behavioral and Brain Science, 8, 26-30. https://doi.org/10.4236/jbbs.2018.81002

Received: November 24, 2017

Accepted: January 8, 2018

Published: January 11, 2018

Copyright $\odot 2018$ by author and Scientific Research Publishing Inc. This work is licensed under the Creative Commons Attribution International License (CC BY 4.0).

http://creativecommons.org/licenses/by/4.0/

(c) (i) Open Access

\begin{abstract}
It is a syndrome with a set of signs and symptoms distinct from depression or panic syndrome, which is not characterized by the fear of dying, but by the desire to die in the form of suicide or in another quick way. Unlike depression or panic, it occurs more frequently between 60 and 80 years of age, according to the World Health Organization (WHO) report, which puts Brazil in eighth place among the countries with the highest incidence of suicides in the age range of 70 years. The report estimates a death every 40 seconds in the world, with India ranking first among the countries surveyed, according to the United Nations agency, in the WHO 2012 registries. It can occur in any person, regardless of color, religion, social class or schooling, being more common, however, among men, in the ratio of nine men to two women. It is very common among health practitioners or the self-employed. Causes are related to the general delusion involving body and mind, focusing on the lack of care. By the description of the dictionary, soul is the union of body and spirit, which some prefer to call mind. "Empty Soul" represents the lack of the very essence of life, a total void of wills, a finding of abandonment. For these symptoms or illness, the treatment has followed the line of "antidepressants" aimed at the reuptake of serotonin, such as SSRIs, MAOIs, anxiolytics (benzodiazepines) and painless techniques that reach the brain, used in neurology and psychiatry. We suggest, as a therapeutic idea, the realization of "Healing Workshops", with the support being given in the form of meetings with motivational orientations, through positive stimuli, daily and constant psychotherapies, which the client will attend until cure is verified. This degree of disorder has presented in alarming proportions, especially after 2015. This work is justified by to the dramaticity of the deaths, such as: knife, shot, fall of great height, hunger strikes and forced isolation in prisons or kidnappings. In addition, the Brazilian Institute of Geography and Statistics (IBGE) has estimated, for the year 2025, in Brazil, a population of 32 million elderly people. This manuscript reports signs and symptoms presented by patients who thought it was not worthwhile to continue living.
\end{abstract}




\section{Keywords}

Depression, Panic, Suicide, Soul, Disillusionment

\section{Methodology and Difficulties}

We have selected 20 patients, including 5 families, who went through this type of suffering, whose ultimate goal would be to end their own life on earth. It is necessary to break taboos and tell the truth to save others with the same diagnosis. Many families prefer to hide the cause of death or the reason for the patient's hospitalization. Psychotherapy is assisted by a psychologist [1]; the prescription is made by the psychiatrist, but people with mind problems are often taken to spiritual or faith healers. The methodology is reflective from what we produce as a material for reflection along with the accompaniment of the elderly at home, in medical offices or in wards. It will require us a more linear than rational method to think of a neighboring syndrome of suicide. Phobia, panic attack [2], suicidal will are the symptoms that approach, but sometimes the most important is to give a harmonious multidiscipline care with a single purpose: the cure of the client. There are no specific public policies or hospitals prepared for this type of care [3]. It will be much more difficult in cases of war between nations or economic crises that lead to sudden social upheaval or the sudden collapse of people's financial power. Neglect and signs of suffering due to the elderly's abandonment are the major causes of "wanting to die" because they feel useless and with no purpose.

\section{Commonly Identified Causes That Indicate Problems with the Elderly (Notes Observed in the Cases Studied)}

- Stress, phobia, loneliness and abandonment.

- Lack of care.

- Thinking that the disorder is transient and not perceiving the imminent and real danger.

- Thinking it is a genetic disorder and, therefore, not taking to a specialist.

- Serotonin or cerebral GABA (gabaergic acid) imbalance [4].

- Decreased glucose metabolism, causing difficulty in self-control and relaxation.

- Abrupt lack of money.

- Breaking up in love relationships.

- Accidental death of a loved one.

- Very late diagnosis.

- Traumatic judicial separation.

- Unexpected betrayal.

- Permanent injury with physical incapacity and/or loss of one of the senses.

- Disillusionment with retirement and old age. 
- Unfair imprisonment.

- Prolonged chronic disease with fatal prognosis.

- Total hopelessness.

- An aggravation can occur if there is war in a country where loved ones live. We have constructed a script for screening points that can identify the "Empty Soul” [5].

\section{Common Signs and Symptoms (We Have Only Recorded Signs and Symptoms That Occurred in the Research Cases)}

- Awareness of being old and belonging to a senior citizen code [6].

- Loss of hunger with sudden weight loss without diagnosis of cancer.

- Total sadness that does not improve even with good news.

- Compulsive, intermitente crying.

- Willingness to die accompanied by remorse or the will of all to die with them.

- Desire with lack of choice of how to kill themselves.

- Chest tightening in the form of suffocation.

- Feeling of darkness even during the day.

- Tight heart and deep sadness.

- Loss of direction and path, not knowing where to go.

- Most common occurrence between 60 and 80 years, but sometimes occurring in other ages.

- Escaping for a period of time, without leaving an address and without a justified reason, although not intended to offend others.

- Lack of God, of faith, of hope, of courage and will to live.

- Alternate tachycardia and bradycardia.

- It can occur at any time of the day or night, although it is more common at dusk.

- Lack of contentment or smiles.

- Feeling of abandonment and contempt.

- Lack of joy.

\section{Epidemiology}

Unlike depression and panic, which can occur before the age of 30, the "Empty Soul" occurs frequently after 60 years of age, being, in Brazil, the most frequent suicide rate around 70 years, according to data obtained from the WHO. It occurs three times more often in men than in women, usually after retirement and after problems with friends and/or relatives or sudden fall in the purchasing power of the individual. Perhaps due to age, one the severity of the disorder is only perceived too late. This does not mean that it cannot occur in youth. It will depend on the degree of the trauma and the intensity of the physical, mental or spiritual injury. It is not linked as much to fear as other syndromes [7], but rather to the degree of disappointment or disillusionment. It involves the central nervous system (loss of sleep), peripheral system (tremors), skeletal muscles 
(tightening of the throat and thorax) and especially the mind (fixed idea in death or that living is not worth).

\section{Treatment}

Because of the severity of the symptoms and the shocking answers to the anamnesis questions, the condition may worsen until the physician makes the correct choice regarding the medication and the "patient" conduction. Patients often receive medication to control anxiety (which causes sleep, but does not solve the problem), psychotherapy (which does not resolve to be on alternate days) [8] and antidepressants (which may help in the occurrence of symptoms). There have been reports of success with repetitive, painless transcranial magnetic stimulation. We have proposed the "Healing Workshop", with visits twice a day, follow up in medication administration, optimistic companions and visits of family and friends, always looking for financial and loving solutions.

\section{Discussion and Prognosis}

We not always get success with our procedures. The most important is our change of attitude. We have observed few specific publications concerned with the elderly in the stage of abandonment and depression. A pathology that often, for the patient to improve, depends on the improvement of third parties or close relatives. It is difficult to resolve because it does not always occur with alternating symptoms, but rather presents signs and symptoms that are fulminating with dread or deep disillusionment. If the treatment is not persistent and the follow-up is not close, the disease may return with a fatal recurrence. It is not always linked to alcoholism or drugs, but it is always linked to disappointment, affecting the mind more than the body. Medications may lead to drug dependence, which will be harmful with the interruption of the drug treatment. The proposed treatment should be on a daily basis and with constant and personal follow-up of psychotherapy. We have seen improvement in cases involving physical exercises, medications, physical and spiritual assistance with a prayer chains and exercises that involved faith and religiosity. The greater risk of suicide occurs in the total lack of care, even though in many cases it occurs among physicians and nurses, who have cared for others for years. The purpose of this study is to care for the elderly and to accompany them in their daily lives to capture signs of the soul's illness, so that it does not become "empty". It is important to emphasize the high complexity required by all health studies.

\section{Conclusions and Results}

We have noted the lack of preventive care from a reflection initiated by the observation of the body: physical signs of aging, emotional problems of abandonment, spiritual problems due to the lack of faith, the awareness of being elderly, the non-occupancy of their space in society, empty words and thoughts, lack of will and generalized discouragement. We have certified the total will to die for 
thinking they are not worth living. The reasons focus on the stress caused by hopelessness. Several elderly have been observed and thirty were selected for the study, all aged 70 or older. The selection was made among friends and patients of the nursing home where I was director. When participants were asked about the Christmas Day, we observed differences between the answers of men and women. "Why have not you been visited by your relatives?" Men's answers: "Because I worth nothing anymore and I have no more money." Women's answers: "Because they may be traveling, they must have other commitments, but another day will come." The ratio of the sexes who have the syndrome is nine men to two women. There were no cases of suicide among women, but three among men. Two cases were explained by the family: 1) a physician had been prosecuted for having collected three hundred US dollars to remove a tumor of the lower right eyelid and the result was a small ectropion (eye reduction) for three months. The physician fell into depression and, hidden from the lawyer, paid the three thousand US dollars asked by the former patient, but she did not withdraw the case. He died with a single shot in the ear; 2) a woman betrayed her husband to the pastor of the church and he drank poison. There was a third case of an individual who had attempted suicide four times; when I went to visit him at the hospital, he was standing at the fifth-floor window ready to jump. I said, "I came to say goodbye to you. Come down and give me a hug. Then you jump. Please, I came from afar!" After a while, he got down by a chair and we talked for five hours. I called the whole family, who took over the care for him, and he is alive to this day. All other interviewees are alive and some are better than others.

What we have proposed are, in fact, changes in the existing paradigms, so we could even discuss the need to create a Ministry of Happiness and Joy to implement the new paradigms.

This study opens the gates for future research when it will be possible to report cases and to put in tables the in-depth knowledge.

\section{References}

[1] Whitfield, C.L. (2006) A verdade sobre a depressão: Alternativas para a cura. Editora Cultrix, São Paulo.

[2] Keller, G. (1995) Síndrome do pânico. 5th Edition, Globo, São Paulo.

[3] Demetrio, F.N., Soares, O.T. and Tung, T.C. (2003) Síndrome do Pânico: o que você precisa saber. Ediouro, Rio de Janeiro.

[4] Moreto, M. (2010) O mestre do seu sistema-O caminho de volta da ansiedade e da Síndrome do Pânico. Sá Editora, São Paulo.

[5] Alves Junior, E.D., Org. (2010) Envelhecimento e vida saudável 2. Apicuri, Rio de Janeiro.

[6] Lipovetsky, G. (2005) A era do vazio: Ensaios sobre o individualismo contemporâneo. Manole, Barueri.

[7] Sene-Costa, E. (2006) Universo da depressão. Editora Ágora, São Paulo.

[8] Thase, M.E. and Lang, S.S. (2005) Sair da depressão. Editora Imago, Rio de Janeiro. 